Article

\title{
Factors That Influence Virtual Tourism Holistic Image: The Moderating Role of Sense of Presence
}

\author{
Ling-Long Tsai
}

check for updates

Citation: Tsai, L.-L. Factors That Influence Virtual Tourism Holistic Image: The Moderating Role of Sense of Presence. Sustainability 2022, 14, 467. https://doi.org/10.3390/ su14010467

Academic Editors: Raquel Camprubí and Ariadna Gassiot-Melian

Received: 2 December 2021

Accepted: 30 December 2021

Published: 2 January 2022

Publisher's Note: MDPI stays neutral with regard to jurisdictional claims in published maps and institutional affiliations.

Copyright: (c) 2022 by the author. Licensee MDPI, Basel, Switzerland. This article is an open access article distributed under the terms and conditions of the Creative Commons Attribution (CC BY) license (https:// creativecommons.org/licenses/by/ $4.0 /)$.
Department of Cultural Creative Industries, National Pingtung University, Pingtung 90003, Taiwan; 1lt0214@mail.nptu.edu.tw

\begin{abstract}
The COVID-19 pandemic has dramatically restricted domestic and foreign travel; thus, virtual tourism has become a new option for traveling. As regards virtual tourism, the present study seeks to investigate the effect of tourist involvement on the three components of holistic image, namely cognitive, affective, and conative images; the influence of cognitive, affective, and conative images on the construction of the holistic image; and the moderating effect of sense of presence on the relationships between cognitive, affective, and conative images on the holistic image. Prospective tourists were chosen as research subjects in the present study on non-immersive virtual reality (VR) tourism, or virtual tourism. Participants first watched the $360^{\circ}$ VR tour video of AirPano. Afterward, they filled out an online questionnaire, of which 386 valid samples were collected for analyses. Results show that tourist involvement considerably affects cognitive, affective, and conative images, which significantly influence the holistic image. Furthermore, a sense of presence was found to positively moderate the relationships between (1) cognitive and holistic, (2) affective and holistic, and (3) conative and holistic images. These results may allow tourism marketing organizations to better understand how to strengthen the holistic image in the context of virtual tourism.
\end{abstract}

Keywords: tourist involvement; cognitive image; affective image; conative image; holistic image; sense of presence

\section{Introduction}

Since the COVID-19 outbreak, people have changed the way they travel: they have cut back their use of public transportation and reduced their travel plans to minimize potential risks due to their perception and anxiety regarding the spread of the disease [1]. Since the beginning of the pandemic, a sudden decline in tourism has been observed, which naturally led to a sharp drop in tourism revenues [2]. The impact has been especially dramatic for international tourism because of the difficulties in dealing with the governmental restrictions of foreign countries and the complexities of different languages and cultures. The spillover effects of the slump in tourism have spread across other related hospitality industries, including airlines, restaurants, gift shops, and others [3]. The behavior change is mainly due to risk perception. The COVID-19 pandemic has significantly increased the perception of the risks of traveling, joining tours, traveling to unfamiliar places, and other general hospitality hazards.

Pappas [4] noted that the tourism industry has gradually rebounded, even during what has been called "post-pandemic". Indeed, as the tourism industry adjusts to a general improvement in the pandemic, which is largely due to the development of vaccines and other mitigation strategies, such as masks and ventilation, reducing the negative feelings and risk perceptions of tourists is necessary to revitalize tourism. In many countries, destination marketing organizations have implemented measures to reassure travelers by booking their trips through online platforms, purchasing tickets using QR codes, and maintaining social distancing in queuing areas [5]. Although these measures are helpful, exploring additional innovative and comprehensive ways to meet the safety needs of tourists is still necessary [6]. 
The Internet has increasingly been used during the pandemic as a source of information gathering and as a tool for consumers to communicate with their friends or other tourists. Online channels have become a source of information for tourism planning activities with the development of digital technology. The tourism industry has also undergone a digital transformation such that tourists can experience tourist destinations through virtual reality (VR). Such links to destinations or agents are expected to continue in the postpandemic era, and travelers are increasingly embracing online consumption patterns [7]. Tour guides could demonstrate remote visitors with local cuisine and culture through online travel conventions, in which visitors can use video communication to strengthen the field experience for tourist destinations despite the restriction of people's movement during the pandemic [8].

Virtual tourism involves no physical contact; consequently, issues with social distancing are absent, which is amenable to life during the pandemic [9]. Virtual tourism also provides an informative perspective, allowing prospective tourists to gain detailed knowledge of the destination and an overview of the destination through guided videos [10]. Thus, virtual tourism has considerable potential to benefit the tourism industry before and after the pandemic. Consumers can be encouraged to travel to tourist destinations worldwide through browsing on the Internet [11]. On-site and virtual tourism are expected to exist simultaneously in the future even after the outbreak ends. In a crisis, virtual tourism can meet the security needs and relieve the pressure of tourism demands. Besides, virtual tourism can also stimulate the imagination of users of on-site destinations and enhance the brand value of destinations [12]. Prospective tourists are visitors interested in tourist destinations or activities [13] and usually have a positive preference for destinations and a high willingness to pay for destinations [14]. Therefore, understanding the disposition and motivation of prospective tourists is important in understanding virtual tourism.

Tourist involvement refers to the degree to which tourists are interested in the activity and the emotions that are elicited by the activity under the context of tourism [15]. Involvement is also a reflection of the emotional state of an activity or experience. The degree of tourist involvement has a significant impact on the destination image [16]. Moreover, involvement is regarded as an antecedent to the image of a tourist destination because a personal special on-site experience will elicit positive emotions, such as joy and pleasure [17]. Travelers with high situational and psychological involvement are generally willing to spend additional time collecting information before departure. In addition to recommending attractions to others, they also have high degrees of intention to revisit the destination. The degree of involvement directly affects the revision of the tourist destination image [18]. The involvement of additional individuals in the destination experience helps provide additional characteristics of the destination. Therefore, the degree of involvement is highly associated with the destination image [19]. Relevant studies also support a positive association between involvement and destination image. One study of wine tourism indicated that the high involvement of an individual in wine products facilitated increased information-seeking regarding wine, and prior knowledge and experience of wine formed cognitive images. High product involvement can also trigger positive emotions, leading to high affective and destination images [20]. Personal involvement in aboriginal festivals positively affects the cognitive, affective, and conative images of participants. The cognitive image is influenced by the information and knowledge of the destination [21]. Photos and emotional messages are conducive to the formation of affective images: obvious individual involvement leads to the formation of a strong affective image [21]. A survey of consumers' choices of travel websites shows that the high involvement of consumers in destination websites will have a positive impact on the cognitive and affective images of the destination, ultimately affecting the holistic image [22].

Early research on the formation of the destination image is based on exploring the mental evolution and tourist experience before, during, or after a tour. Crompton [23] defined destination image as tourists' attitudinal concept towards the destination, which is the sum of their beliefs, ideas, and impressions. Gunn [24] believed that tourists would revise or 
change their views on the destination image with their mental accumulation, information acquisition, and travel experience. Later on, Baloglu and McCleary [25] advocated that the destination image is composed of the cognitive and affective image, and pointed out that affective image is influenced by the cognitive image. Prayag [26] stated that although no consensus on the definition of the destination image is available, most researchers generally believe that the destination image comprises the following three image components: cognitive, affective, and conative images. The cognitive image is an impression assessment of the characteristics of the destination, the affective image represents the emotional response of an individual to the destination, and the conative image is the action of an individual based on the knowledge of two preceding components [27]. Pike and Ryan [28] analyzed the market positioning of tourism by comparing cognitive, affective, and conative images. They explored cognitive images from the perspective of an importance-performance analysis and expressed the affective images of tourists considering emotional response, while the likelihood of visiting a destination was the conative image. Other scholars posited that the three destination image components have an interactive relationship. For example, Myers [29] argued that the three destination image components have a sequential influence relationship. Alternatives will be developed after consumers realize their needs, which is the cognitive stage. The affective stage is involved in evaluating the alternatives, while the conative stage emerges when choosing a product. In the study of green hotel issues, Lee et al. [30] also considered that the holistic image, which comprises cognitive, affective, and conative images, was sequentially related.

Agapito et al. [31] explored the interactive influence of the three destination image components and obtained results similar to the previous studies. In addition to the influence of cognitive and affective images on the conative image, the affective image was found to serve a mediating role; that is, the cognitive image influenced the conative image through the affective image. However, other researchers believe in the existence of a parallel relationship, which separately and directly affects the formation of the holistic impression. Although Gartner [32] initially proposed that cognitive, affective, and conative images were hierarchically related, later scholars believed that the three destination image components can be conceptualized as three diverse components that simultaneously affect holistic image [33,34]. In their study of tourists' risk perception, Loureiro and Jesus [35] also agreed with the aforementioned view regarding the three destination image components as variables affecting the holistic image.

Uhm et al. [36] believed that VR environments can enhance the sense of presence of an individual and enable users to have a strong sense of cognitive and affective images. The research of Yung et al. [37] on virtual cruise tourism showed that VR triggers markedly pronounced emotional responses. Spatial presence can provide the participants with a sense of feeling as if they are in a particular destination, thus encouraging strong intentions to travel. Alyahya and McLean [38] divided presence into the perception of arriving and leaving the physical environment and proposed that the sense of presence is a vital factor affecting the behavior and attitude of tourists. Virtual tourism can enhance the sense of immersion of a user, improve the cognitive process of information, and activate mental imagination, thus increasing the perception of presence. Zhang et al. [39] considered that live streaming of tourist locations allows viewers to form an impression of the destination based on the obtained information, while a sense of presence can increase the trust of the destination and provide a comprehensive understanding of the destination. In addition, Yang et al. [40] posited that the VR experience can enhance the sense of presence tourists feel toward these destinations. VR technology-based tourism establishes a sense of presence and creates first impressions of the destination, which then has a strong impact on the satisfaction of virtual tourism. Moreover, such a type of tourism enables tourists to focus on the feeling of being in a certain place, creating a relatively real tourism experience to achieve psychological well-being [40]. Cao et al. [41] studied narrative tourism videos and found that this kind of presentation is similar to transporting tourists to the destination, which can reduce their risk perception. Tourists can have a sense of presence as if they are 
in the destination and can immerse themselves in the context of the attraction through the viewing of short videos. Bogicevic et al. [42] stated that presence can increase interactivity, and interactive virtual environments, such as $360^{\circ}$ web-based tours, can help travelers replace information searching. The travel experience will be rich, and the travelers will be encouraged to travel when the experience is real. Tussyadiah et al. [43] put participants in a virtual environment where they were walking through a destination and found that the sense of presence positively changed attitudes toward the destination. The ability of individuals to place themselves in the destination also constructs a sense of spatial presence in the virtual setting. Thus, a strong sense of presence increases the interest and favorability of the tourist destination. Consequently, the traveler's intention to visit the attraction will also increase.

Previous studies (e.g., Kuhzady [44]) have shown that tourist involvement has an impact on the holistic image of tourist sites; however, these studies did not involve virtual tourism. Furthermore, past research results reveal that virtual tourism plays an indispensable role in alleviating public demand for tourism under the impact of COVID-19 despite the increased preference of tourists for on-site tourism [39]. Zhang et al. [39] showed that the sense of presence was formed by live streaming assisted viewers in the formation of destination images. However, the moderating effect of presence on the holistic image has not been tested, and investigations have not been conducted in the context of virtual tourism. Thus, this academic gap must be investigated. Therefore, the present study first constructs the influence of tourist involvement on the antecedents of the holistic image, including cognitive, affective, and conative images, based on the characteristics of virtual tourism. This study then investigates the influence of the three destination image components on the formation of the holistic image. In addition, this study seeks to understand effectively the moderating effect of presence on various images of the holistic image in the context of virtual tourism. The validation of the research model is helpful to understand the formation process of virtual tourism images and evaluate the explanatory power of each model component. The results of this study can provide information for tourism operators on handling virtual tourism, finding suitable target markets, understanding the perception of prospective tourists on the holistic image of tourism destinations, and contributing to the development of effective marketing strategies that encourage all types of tourism.

\section{Background and Hypotheses}

\subsection{Virtual Tourism}

Virtual tourism is an environment created by computers, allowing users to interact with different stimuli and experience scenery and sound effects through virtual media to achieve the sensation of being in a particular place in reality [45]. Virtual tourism may not be a substitute for live activities but can inspire users to participate in upcoming events [46]. The application of VR in the tourism industry can provide tourists with destination information, enhance the global interactions among consumers, and promote the enjoyment of consumption [47]. Virtual tourism is also a convenient tool that allows users to have an in-depth evaluation without having to arrive at the destination and form their image through this experience, thus influencing the decision of destination selection [11]. The adoption of virtual tourism can improve the "virtual accessibility" for users, providing an option of access for the general public to evaluate when destinations are remote, expensive, or dangerous [48]. Virtual tourism can provide tourists with a complete image of the hotel or destination; thus, people who want to travel can be familiarized with unfamiliar destinations through virtual tourism and reduce the perceived risk or anxiety of tourists [49]. Virtual tourism can even present tourists the opportunity to experience scenic spots and sites that no longer exist [50]. In addition, virtual tourism provides a remarkable contribution to maintaining the sustainability of the environment because it is environmentally friendly [51].

The viewpoints of researchers are similar despite the absence of a consensus on the definition of virtual tourism. Koutsoudis et al. [52] advocated virtual tourism, in which 
visitors watch through a computer's Internet connection, use a terminal and a mouse, and interact with the simulated settings. Spielmann and Mantonakis [53] suggested that virtual tourism is a simulated context constructed from a series of images or videos, supplemented by written narration, acoustic guidance, or sound effects, in an attempt to represent the genuine site experience authentically. Kim and Hall [54] revealed that virtual tourism is designed to experience or travel by using VR devices to watch $360^{\circ}$ and drone videos to gain the destination information and have fun in tourism-related activities. Virtual tourism can establish a connection with prospective tourists through the 3D virtual world, providing prospective customers with an affluent experience by searching destinations [55]. Beck et al. [56] conducted a detailed classification and definition based on the immersion degree of a user. They considered that VR in the context of tourism aims to create a virtual environment in a $360^{\circ}$ or synthetic way, obtain a virtual tourism experience by stimulating the visual senses, and divide the virtual tourism into three (non-, semi-, or fully) immersive virtual tourism classifications. The difference lies in the devices the user utilizes to access the virtual environment. Non-immersive virtual tourism uses computers to watch $360^{\circ}$ videos, while semi-immersive virtual tourism projects $360^{\circ}$ videos onto a large screen or wall. Fully immersive virtual tourism creates an environment isolated from the real world through head-mounted devices and views from $360^{\circ}$ videos in this context. Beck et al. [56] defined that non-immersive virtual tourism uses combined synthetic or $360^{\circ}$ realistic content to stimulate the vision and senses of users through the presentation of conventional computer screens to complete their virtual touristic experiences. Zhang et al. [12] believed that virtual tourism contains broad and narrow concepts. In a narrow sense, virtual tourism allows tourists to experience a three-dimensional virtual environment through VR visual technology. In a broad sense, virtual tourism allows tourists to acquire knowledge and information through any access in a non-immersive way. El-said and Aziz [10] considered that virtual tourism is a simulation of existing sites composed of a series of video images. Therefore, virtual tourism referred to in the current study follows the broad definition, conducting a survey of prospective tourists in a non-immersive way of watching $360^{\circ}$ videos.

\subsection{Tourist Involvement and Destination Image}

Molinillo et al. [57] selected three social media sites with high global Internet penetration, including Facebook, YouTube, and Instagram, sharing profiles, photos, and videos on these platforms. The experiment confirmed that the degree of involvement in the Facebook and Instagram groups positively influenced the cognitive and affective images of the destination. Researching tourists and residents in six different locations of $\mathrm{China}, \mathrm{Wu}$ and Liang [20] revealed that the involvement of wine products had a significant impact on the cognitive and affective images of the tourist destination. Through observations on the mental processing of video tourism, Fu et al. [58] interviewed white-collar workers on the street regarding TV travel programs of reality shows. They concluded that different extents of audience involvement affected their cognitive and affective images of destinations, influencing their behavioral intentions. Moreover, Scarpi et al. [59] noted that the level of event involvement notably affected the intention of non-adjacent tourists to revisit the destination. Thus, speculating that tourist involvement will affect the cognitive, affective, and conative images of the tourist destination is reasonable based on the above study findings. Therefore, the following hypotheses are formally proposed.

Hypothesis 1 (H1). Tourist involvement positively influences tourists' cognitive image of virtual tourism destinations.

Hypothesis 2 (H2). Tourist involvement positively influences tourists' affective image of virtual tourism destinations. 
Hypothesis 3 (H3). Tourist involvement positively influences tourists' conative image of virtual tourism destinations.

\subsection{Formation of Holistic Image}

Sultan et al. [60] indicated that prospective tourists prefer to browse comments and opinions on social media when searching travel information, which can be classified into two categories. Tour-operator-generated content aims to enhance consumers' trust in travel information, while user-generated content attempts to reduce the uncertainty and risk of travel. The two kinds of information content form the holistic image of tourist destinations through the influence of cognitive and affective images. By investigating Eilat visitors and residents, Stylidis et al. [61] found that cognitive and affective images were important antecedents in both groups to shape the holistic image and further influenced subsequent recommendation intentions. The affective image has a stronger effect than the cognitive image in the process of forming the holistic image of tourists. Wang and Hsu [62] surveyed tourists in famous world heritage sites in China, and their results illustrated that cognitive and affective images were two main factors that constituted the holistic image of tourists. Lin et al. [63] inquired residents regarding their viewpoints on natural scenery, developed scenery, and theme parks. The established research model validated that the cognitive and affective images affect the formation of the holistic image. The holistic image of residents among three types of spots will directly cause the difference in the degree of destination preference. Stylos et al. [33] studied revisit intentions and found that the cognitive, affective, and conative images may have different levels of impact on the holistic image of the British and Russian tourists. Their results established that the three destination image components have a direct association with the holistic image, and the holistic image also has a positive and direct influence on the intention of tourists to revisit. Afshardoost and Eshaghi [64] summarized two major views from 87 studies on destination image through a meta-analysis. Some researchers explored the mutual influence between cognitive, affective, and conative images. Conversely, other scholars [33,34] believed that the holistic image is influenced by affective, cognitive, and conative images. The following hypotheses are developed on the basis of the aforementioned reasoning.

Hypothesis 4 (H4). Tourists' cognitive image positively influences their holistic image of virtual tourism destinations.

Hypothesis 5 (H5). Tourists' affective image positively influences their holistic image of virtual tourism destinations.

Hypothesis 6 (H6). Tourists' conative image positively influences their holistic image of virtual tourism destinations.

\subsection{Sense of Presence and its Moderating Role}

Presence is related to the sensation level of users of "being there" in a virtual setting [65]. A sense of isolation from the real world, usually in the form of human-computer interaction, is felt when the viewer is immersed in a virtual environment. The degree of presence in a VR travel experience depends on the feeling of being in a virtual environment shift from the real world. A consensus on the categories and definitions of presence, which include a sense of presence, spatial presence, telepresence, and social presence, is currently unavailable. Yang et al. [40] proposed that presence should include two types, namely sense of presence and telepresence. The sense of presence is the immersion and experience felt in a virtual environment, while telepresence is the subjective awareness presented in an artificial or remote environment rather than a real one. The sense of presence is measured when users undergo mediated experiences in real and virtual places. If the perception of respondents in a virtual environment is tested, then the telepresence is assessed. Presence and telepresence will influence the affective-motivational state. For example, enjoyment 
and involvement are elements of the affective-motivational state. Fraustino et al. [66] considered that spatial presence should include telepresence and spatial presence. The $360^{\circ} \mathrm{VR}$ video experience can enhance the sense of spatial presence. The sense of spatial presence can be improved through $360^{\circ}$-rich media presentation and immersion, and cognitive and affective responses can be advanced. Zhang et al. [39] believed that social presence comprises the production presence, interaction, and destination image presence, which can further generate trust toward destinations and then influence the visit intention of tourists. The destination image in the context of watching live streaming can be formed from the obtained information.

Previous studies have found that the influence of the sense of presence in the virtual environment can be demonstrated. Wei et al. [67] advocated that users can perceive a high sense of presence in a virtual environment. The perception of presence is likely to elicit emotions, such as happiness and enjoyment, through VR immersion. Alyahya and McLean [38] claimed that VR can advance the sense of presence, and the sense of existence is a psychological state of feeling completely immersed in the virtual world and a feeling of "being there" in the computer-mediated environment. The cognitive processing of mental images can stimulate a high level of presence in the context of a high sensory VR experience. Moreover, the perception of presence will affect the attitude of tourism consumers toward destinations and their intention to visit. Uhm et al. [36] also speculated that emotional stimulation can be enhanced in the VR environment. The sense of presence has a significant impact on the affective results: a strong sense of presence by the user elicits remarkably intense emotions. Yung et al. [68] found that VR enabled prospective travelers to have strong cognitive and affective components of destination images. The sense of presence can also promote the understanding, entertainment, and perception of the destination for prospective travelers. A VR experience provides richer information than traditional media, while the richness of the VR environment contributes to a high sense of presence and affects the cognitive impression of prospective visitors.

In addition, the sense of presence is related to the tourism image of tourists and the holistic image of the destination. Banos et al. [69] believed that presence is a factor of cognition, while immersion is the degree of physical awareness of external information. Experiments of two virtual environments confirmed that affective content and immersion have a significant impact on the sense of presence. Tussyadiah et al. [43] considered that the sense of presence can be classified into two categories of the VR experience: during VR experience and post-VR experience. The sense of presence will affect the enjoyment of VR tourism in the process of experience. In addition, the sense of presence will induce changes in the viewer's attitude toward the destination and affect their intention of an actual visit in the stage of the post-VR experience. Wu and Lai [70] invited participants to watch the renowned mountain scenery with a $360^{\circ}$ panoramic sight. Their results showed that viewers could effectively understand the tourist destination and further develop a positive cognitive image when they had a strong sense of presence. Moreover, the viewer's sense of presence of scenic spots helps build an affective connection with the destination and form positive affective images. Furthermore, a strong sense of presence that viewers experience contributes to the formation of a fantastic holistic image of the destination. Cao et al. [41] found that the narrative transportation introduced by short tourism videos would affect the sense of presence of prospective tourists toward the destination, and the perceived presence would also influence the narrative persuasion of videos and their destination brand attitudes. Hyun et al. [71] surveyed respondents with various virtual information contents provided on the website, and their results illustrated that telepresence had a direct and significant impact on virtual cognitive and conative images. However, no direct impact on the affective image was observed. The current study reasonably speculates that the effect of the three destination image components on the holistic image could be enhanced when the strength of the sense of presence is relatively high based on the above research findings. Hence, the following hypotheses are proposed. 
Hypothesis 7 (H7). Tourists' sense of presence positively moderates the relationship between destination cognitive and holistic images of tourists.

Hypothesis 8 (H8). Tourists' sense of presence positively moderates the relationship between destination affective and holistic images of tourists.

Hypothesis 9 (H9). Tourists' sense of presence positively moderates the relationship between destination conative and holistic images of tourists.

\section{Research Methodology}

\subsection{Survey Procedure}

This study attempts to explore the formation process of the holistic image of a tourist destination by immersing prospective tourists in a virtual tourism context through connecting $360^{\circ}$ scenic videos. The classification of virtual tourism types by Beck et al. [56] indicated that the viewing mode adopted in the current study is non-immersive virtual tourism because the viewers experience the virtual tourism through their computers. The non-immersed virtual tourism stimulates the visual senses of viewers and provides them with a control measure of the virtual tourism experience considering autonomy to control the $360^{\circ}$ video content. The subjects of this study are prospective tourists, representing consumers who have never been to tourist destinations. Therefore, considering the popularity of scenic spots and prioritizing scenic areas that most people have never been to is necessary when selecting videos for respondents to watch. Statistics from the Taiwan Tourist Bureau released in September 2021 reported that only 3000 Taiwanese outbound travelers went to Africa in the past three years. Therefore, the $360^{\circ}$ video of "Victoria Falls: The Biggest Waterfall of Africa" by Airpano (Figure 1) was selected as the video to be watched before filling out the questionnaire. In addition to the $360^{\circ}$ panoramic scenery, the video also has narration and captions to help viewers understand the content of the film. The following filter questions were asked before answering the formal questions to find appropriate respondents as the source of the questionnaire analysis: (1) How long did you watch this video?; (2) Which countries have you traveled to in the last five years?; (3) What kind of scenery does this video show? Respondents were excluded if they had (1) traveled to Africa in the past five years; (2) watched this video for less than two minutes; or (3) failed to name a waterfall as the scenic spot. The respondents were invited to answer the formal questions after completing the filtering items. Those who completed the questionnaire were selected to enter the next analysis stage.
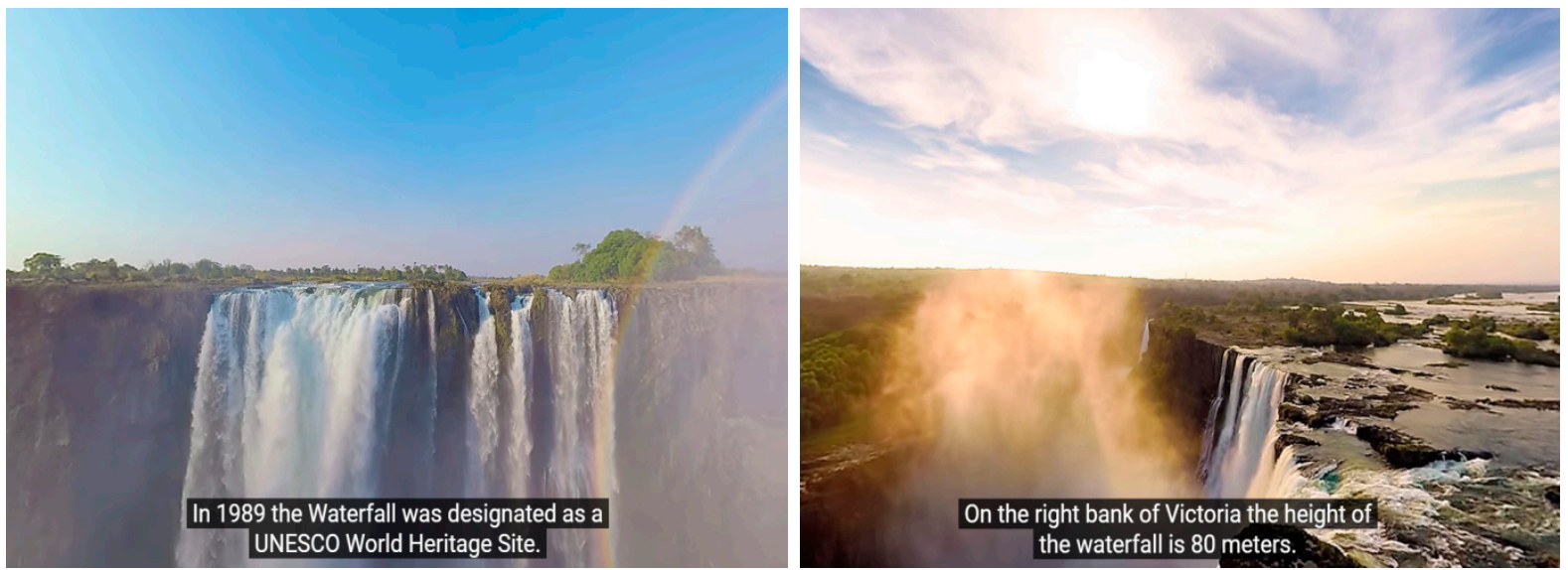

Figure 1. Victoria Falls: the biggest waterfall of Africa. 


\subsection{Study Measures}

This study adopts six constructs based on past studies, and the measurement items of the questionnaire are from past confirmatory results. The structure of the constructs comprises tourist involvement, cognitive image, affective image, conative image, holistic image, and sense of presence. A total of 25 items comprised the survey questionnaire, as presented in Figure 2. Five items were adapted from prior research $[44,72]$ to measure tourist involvement. Four items of the cognitive image from Kim et al. [27] and Kim et al. [73] were used. Four questions were derived from $\mathrm{Wu}$ and Liang [20] to evaluate the affective images. Four items were taken from Kim et al. [27] and Stylidis [74] to assess the conative images. Four questions were drawn from prior research $[44,75]$ to measure holistic images. The sense of presence was estimated by utilizing four items derived from Yang et al. [40]. All questions were designed by a seven-point Likert scale ranging from (1) strongly disagree to (7) strongly agree. In addition, six questions regarding personal background were included and listed after the structural questions. The survey items were originally generated in English and then translated into Chinese. The meanings were examined by experts proficient in Chinese and English and revised to conform to the principles of clear meaning and logical reasoning. The questionnaire was then reviewed by three tourism-related researchers, and the statements of the questionnaire were slightly adjusted to improve the content validity of the questionnaire. In addition, the pilot study was conducted by 12 graduate students, who provided comments on the questions and removed ambiguous or inarticulate sentences. The modified version was utilized for the formal survey questionnaire (see Appendix A).

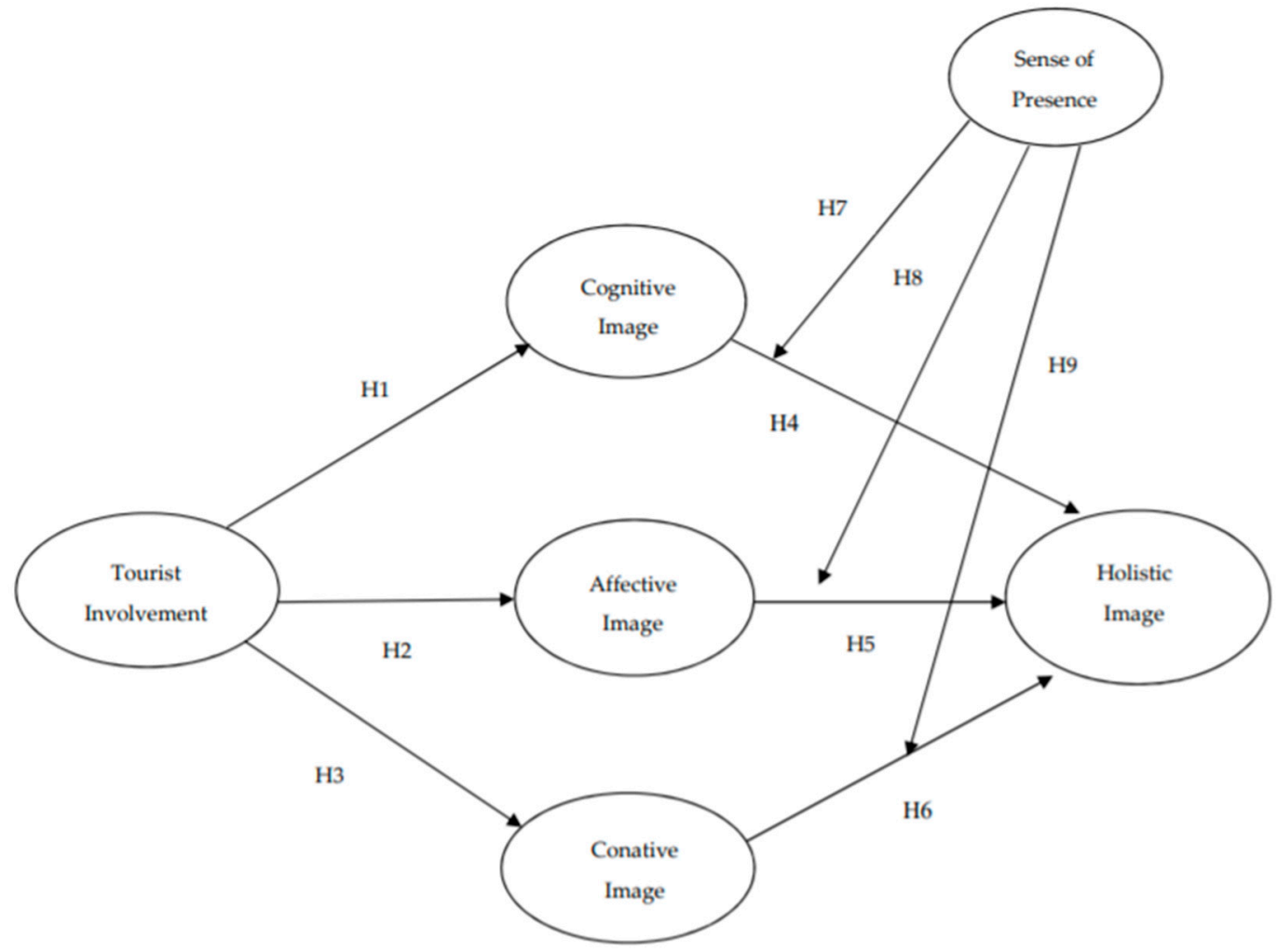

Figure 2. The hypotheses and the research model.

\subsection{Data Collection}

An online questionnaire was adopted in this study considering the cost and efficiency of the survey implementation and reaching a broad number of tourism consumers. A live survey URL was linked on the travel discussion board and blog, briefly stating the survey for collecting data and offering an invitation for prospective tourists to participate in the survey. Therefore, the respondents could understand that this survey was only to identify 
the issues regarding virtual tourism before answering the question, and the questionnaire focused on the Taiwanese above 18 years old. A total of 1245 people responded to the questionnaire in a period of approximately 3.5 months, ranging from July 2021 to October 2021. Respondents must have satisfied the following conditions before the screening questions were provided: (1) watch the video for more than two minutes, (2) no recent travel to Africa in the last five years, and (3) provide the right answer on the scenery theme of waterfalls. A total of 674 people met the requirements of screening in the next phase of the analysis after removing 288 inappropriate answers and incomplete background information. Finally, 386 valid samples were used for the analysis, representing a response rate of $57.3 \%$.

\subsection{Data Analysis}

The partial least squares structural equation modeling (PLS-SEM) analysis was employed in this study to test the proposed research model and confirm hypotheses for subsequent reasons. First, different from conventional SEM, PLS-SEM has a minimal criteria threshold for sample size, measurement scales, and residual distributions to verify a model with the bootstrap resampling technique as a non-parametric method [76], rather than the covariance-based SEM analyses. Second, the PLS-SEM can simultaneously analyze reflective and formative indicators with second-order factors in the research model [77]. Third, the PLS-SEM is considered to be more suitable for the verification of complex models or a multigroup analysis than conventional SEM [78]. Therefore, SmartPLS 3.2.8 was utilized in this study to analyze the measurement and structural models.

\section{Results}

\subsection{Sample Profile}

The survey results indicate that the proportion of male respondents (50.8\%) was approximately equal to female respondents (49.2\%). Almost three-quarters of the respondents were 26 to 55 years old. More than $80 \%$ of respondents had a university degree or above. Approximately $45 \%$ had monthly earnings of more than $\$ 2000$. Full-time employees accounted for the most earnings (46.6\%), followed by part-time employees $(16.6 \%)$. The highest trip frequency was three to six times (46.1\%) per year. Table 1 presents the full profile of the research sample.

\subsection{Analysis of the Measurement Model}

This study followed the two-step approach of Anderson and Gerbing [79] to verify and test the model. The reliability and validity of the model were examined through the model evaluation of the PLS-SEM [80]. In the measurement model as presented in Table 2, the composite reliability and Cronbach's alpha value of each construct were larger than 0.7 based on the criteria recently recommended by Hair et al. [81]. The item loadings and average variance extracted (AVE) were used for the examination of the evaluation of convergent validity. All the item loadings were larger than 0.70 , while the AVE value was larger than 0.50 , indicating that the measurement model had high-quality convergent validity. Table 3 reveals that the discriminant validity was tested in accordance with the Fornell-Larcker criterion. The discriminant validity was evaluated by comparing the correlations between structure and AVE value. All structures showed proper discriminant validity because all correlations were lower than the square root of AVE. 
Table 1. Respondent profile.

\begin{tabular}{|c|c|c|c|}
\hline Characteristics & Value & Frequency & Percentage \\
\hline \multirow[t]{2}{*}{ Gender } & Male & 196 & 50.8 \\
\hline & Female & 190 & 49.2 \\
\hline \multirow[t]{5}{*}{ Age } & $18-25$ years & 22 & 5.7 \\
\hline & 26-35 years & 105 & 27.2 \\
\hline & $36-45$ years & 81 & 21.0 \\
\hline & $46-55$ years & 106 & 27.5 \\
\hline & Above 55 & 72 & 18.6 \\
\hline \multirow[t]{3}{*}{ Education } & High school or below & 53 & 13.7 \\
\hline & College or university & 238 & 61.7 \\
\hline & Graduate school or above & 95 & 24.6 \\
\hline \multirow[t]{5}{*}{ Monthly Income } & Below USD\$ 500 & 47 & 12.2 \\
\hline & USD\$ 500-1000 & 83 & 21.5 \\
\hline & USD\$ 1000-2000 & 77 & 19.9 \\
\hline & USD\$ 2000-3000 & 93 & 24.1 \\
\hline & Above USD\$ 3000 & 86 & 22.3 \\
\hline \multirow[t]{5}{*}{ Occupation } & Student & 56 & 14.5 \\
\hline & Employed full time & 180 & 46.6 \\
\hline & Employed part time & 64 & 16.6 \\
\hline & Unemployed & 51 & 13.2 \\
\hline & Retired & 35 & 9.1 \\
\hline \multirow[t]{4}{*}{ Trip Frequency } & Below 2 times per year & 103 & 26.7 \\
\hline & 3 to 6 times per year & 178 & 46.1 \\
\hline & 7 to 9 times per year & 69 & 17.9 \\
\hline & Above 10 times per year & 36 & 9.3 \\
\hline
\end{tabular}

Table 2. Measurement model assessment.

\begin{tabular}{cccccccc}
\hline Construct & Items & Mean & S.D. & Loading & $\alpha$ & AVE & C.R. \\
\hline Tourist Involvement (Inv) & Inv1 & 5.48 & 0.978 & 0.783 & 0.830 & 0.595 & 0.880 \\
\hline & Inv2 & 5.63 & 0.967 & 0.814 & & & \\
\hline & Inv3 & 5.96 & 0.965 & 0.735 & & & \\
\hline & Inv4 & 6.37 & 0.852 & 0.772 & & & \\
\hline & Inv5 & 6.18 & 0.927 & 0.749 & & & \\
\hline Cognitive Image (Cog) & Gog1 & 6.18 & 0.948 & 0.899 & 0.915 & 0.797 & \\
\hline & Cog2 & 6.13 & 0.992 & 0.912 & & & \\
\hline & Cog3 & 6.11 & 1.015 & 0.897 & & & \\
\hline & Cog4 & 6.24 & 0.996 & 0.860 & & & \\
\hline Affective Image (Aff) & Aff1 & 5.77 & 1.076 & 0.904 & 0.908 & 0.784 & \\
\hline & Aff2 & 5.89 & 1.036 & 0.891 & & & \\
\hline & Aff3 & 5.64 & 1.132 & 0.901 & & & \\
\hline & Aff4 & 5.68 & 1.189 & 0.846 & & & \\
\hline
\end{tabular}


Table 2. Cont.

\begin{tabular}{cccccccc}
\hline Construct & Items & Mean & S.D. & Loading & $\alpha$ & AVE & C.R. \\
\hline Conative Image (Con) & Con1 & 6.19 & 1.015 & 0.829 & 0.886 & 0.746 & 0.921 \\
\hline & Con2 & 6.02 & 1.044 & 0.891 & & & \\
\hline & Con3 & 5.73 & 1.296 & 0.901 & & & \\
\hline Holistic Image (Hol) & Hol1 & 5.70 & 1.240 & 0.901 & 0.892 & 0.756 & 0.925 \\
\hline & Hol2 & 5.83 & 1.099 & 0.888 & & & \\
\hline & Hol3 & 5.86 & 1.164 & 0.871 & & & \\
\hline & Hol4 & 6.17 & 1.000 & 0.813 & & & \\
\hline
\end{tabular}

Note: $\alpha=$ Cronbach's alpha; AVE = average variance extracted; C.R. = composite reliability; S.D. = standard deviation.

Table 3. Discriminant validity (Fornell-Larcker criterion).

\begin{tabular}{cccccc}
\hline Construct & Aff & Cog & Con & Hol & Inv \\
\hline Aff & $\mathbf{0 . 8 8 6}$ & & & & \\
\hline Cog & 0.690 & $\mathbf{0 . 8 9 2}$ & & & \\
\hline Con & 0.668 & 0.717 & $\mathbf{0 . 8 6 4}$ & & \\
\hline Hol & 0.689 & 0.703 & 0.822 & $\mathbf{0 . 8 6 9}$ & $\mathbf{0 . 7 7 1}$ \\
\hline Inv & 0.605 & 0.704 & 0.690 & 0.673 &
\end{tabular}

\subsection{Analysis of the Structural Model}

Six hypotheses were developed on the basis of the research framework for testing. The hypothesis relationships established by the model were evaluated on the basis of the criteria established by Hair et al. [81] considering path coefficients $(\beta)$, explanatory variances $\left(R^{2}\right)$ of the dependent variables, and significance levels obtained by the bootstrapping resampling method [77]. Table 4 shows that all the $p$-values were less than 0.05 , supporting the hypotheses of the structural model. The results illustrate that tourist involvement was positively correlated with cognitive image $(\beta=0.704, t=20.945)$, affective image $(\beta=0.605$, $\mathrm{t}=16.279)$, and conative image $(\beta=0.690, \mathrm{t}=20.151)$, thereby respectively supporting $\mathrm{H} 1, \mathrm{H} 2$, and $\mathrm{H} 3$. In addition, the validated data showed that cognitive image $(\beta=0.150$, $\mathrm{t}=2.902)$, affective image $(\beta=0.196, \mathrm{t}=4.192)$, and conative image $(\beta=0.583, \mathrm{t}=10.468)$, had a significant positive impact on holistic image, thus respectively supporting $\mathrm{H} 4, \mathrm{H} 5$, and H6. Subsequently, the $R^{2}$ and $Q^{2}$ values of the predictive variables were used to evaluate the predictive power of the model. Results showed that all $\mathrm{R}^{2}$ values (Cog: 0.496; Aff: 0.366; Con: 0.475; Hol: 0.720) were higher than those recommended by Falk and Miller [82], which means that $R^{2}$ should be larger than $0.10 . Q^{2}$ was then used to estimate the accuracy of the structural model in predicting the observed values [81]. The results showed that all Stone-Geisser $Q^{2}$ values (Cog: 0.389; Aff: 0.282; Con: 0.351; Hol: 0.536) were positive, indicating that the model had sufficient predictive relevance. Finally, the results of $\mathrm{H} 1, \mathrm{H} 2, \mathrm{H} 3$, and $\mathrm{H} 6$ demonstrated strong effects considering the index of $\mathrm{f}^{2}$ (0.02, small; 0.15 , medium; 0.35 , strong) according to Cohen [83], and only H4 and H5 demonstrated medium to small effects. 
Table 4. Structural model results.

\begin{tabular}{cccccc}
\hline Hypothesis & Paths & $\boldsymbol{\beta}$ & $\mathbf{t}$-Value & $\mathbf{f}^{\mathbf{2}}$ & Remarks \\
\hline H1 & Inv $\rightarrow$ Cog & 0.704 & $20.945^{* * *}$ & 0.983 & Supported \\
\hline H2 & Inv $\rightarrow$ Aff & 0.605 & $16.279^{* * *}$ & 0.578 & Supported \\
\hline H3 & Inv $\rightarrow$ Con & 0.690 & $20.151^{* * *}$ & 0.907 & Supported \\
\hline H4 & Cog $\rightarrow$ Hol & 0.150 & $2.902^{* *}$ & 0.033 & Supported \\
\hline H5 & Aff $\rightarrow$ Hol & 0.196 & $4.192^{* * *}$ & 0.063 & Supported \\
\hline H6 & Con $\rightarrow$ Hol & 0.583 & $10.468^{* * *}$ & 0.520 & Supported \\
\hline
\end{tabular}

Note: ${ }^{* * *} p<0.01,{ }^{* *} p<0.05, \operatorname{Cog}: \mathrm{R}^{2}=0.496, \mathrm{Q}^{2}=0.389$; Aff: $\mathrm{R}^{2}=0.366, \mathrm{Q}^{2}=0.282$; Con: $\mathrm{R}^{2}=0.475, \mathrm{Q}^{2}=0.351$ Hol: $\mathrm{R}^{2}=0.720, \mathrm{Q}^{2}=0.536$.

\subsection{Moderating Effect}

The PLS method suggested by Fassott et al. [84] was employed to verify the moderating effect of the sense of presence in the research model, and hypotheses 7 to 9 were tested as presented in Table 5. First, considering the effect of the cognitive image on the holistic image, a significant effect in the high sense of presence group $(0.069, \mathrm{t}$-value $=2.068, p<0.5)$ was observed, thus supporting hypothesis 7 . Second, in the case of the affective image influencing the holistic image, the affective image had a significant effect in the high sense of presence group $(0.069, \mathrm{t}$-value $=2.068, p<0.5)$; hence, hypothesis 8 was supported . Last, in the case of the conative image affecting the holistic image, a significant effect was observed in the high sense of presence group $(0.100$, $\mathrm{t}$-value $=2.389, p<0.5)$. Consequently, H9 was also confirmed.

Table 5. Moderating effects.

\begin{tabular}{cccccc}
\hline Hypothesis & Paths & $\boldsymbol{\beta}$ & $\mathbf{t}$-Value & $\boldsymbol{p}$-Value & Moderation \\
\hline H7 & Pre $\times$ Cog $\rightarrow$ Hol & 0.069 & $2.068^{*}$ & 0.039 & Yes \\
\hline H8 & Pre $\times$ Aff $\rightarrow$ Hol & 0.077 & $1.990^{*}$ & 0.047 & Yes \\
\hline H9 & Pre $\times$ Con $\rightarrow$ Hol & 0.100 & $2.389 *$ & 0.017 & Yes \\
\hline Note: ${ }^{*} p 0.1$. & & & & &
\end{tabular}

\section{Discussions}

First, the research model is established on the separate influences of cognitive, affective, and conative images on the holistic image [33,34]. One critical antecedent, which is tourist involvement, affects the formulation of the three destination image components. The empirical results illustrate that tourist involvement has robust positive effects on cognitive image $(\beta=0.704, p<0.001)$, affective image $(\beta=0.605, p<0.001)$, and conative image $(\beta=0.690, p<0.001)$. This finding denotes the following: if tourists are interested in or motivated toward a destination, then positive tourism images regarding the vacation place will be formed. Second, cognitive image $(\beta=0.150, p<0.01)$, affective image ( $\beta=0.196$, $p<0.001)$, and conative image $(\beta=0.583, p<0.001)$ have a high impact on the formation of the holistic image. This finding indicates that the three destination image components have positive contributions to the holistic image, especially the conative image, which has the boldest influence on the shape of the holistic image of tourists. In addition, the degree of explanation of the three destination image components indicates that cognitive, affective, and conative images present a solid predictive power $\left(R^{2}=0.720\right)$ for the holistic images. Third, the findings of the research also identify the moderating role of a sense of presence. Thus, the sense of presence has a positive effect on the relationship between cognition and holistic image, affective and holistic image, as well as conative and holistic image. Furthermore, comparing the two other images (cognitive and affective), the sense of presence has a relatively strong effect $(\beta=0.100, p<0.05)$ on the conative and holistic images. If the sense of presence of prospective tourists is strong when they watch VR videos through 
computers, then they may effectively experience the cognitive, affective, and conative images of the tourist destination, improving the holistic image of the tourist destination.

\section{Conclusions and Implications}

\subsection{Conclusions}

This study investigates, in the context of COVID-19, the factors related to the formation of prospective tourists' holistic image of virtual tourism destinations. The proposed model is constructed to explore the influence of tourist involvement on the antecedents of holistic image and the influencing factors that shape the holistic image. In addition, this study also explores the moderating effect of sense of presence on the configuration of holistic image. Research findings confirm that holistic image formation is determined by three destination image components: cognitive, affective, and conative. Results also demonstrate that the degree of prospective tourists' involvement can effectively predict these three image components of the holistic tourist destination image. Furthermore, the moderating effect of sense of presence implies that the holistic image of prospective tourists' virtual tourism can be strengthened through the enhancement of a sense of presence.

\subsection{Theoretical Implications}

Extended from the holistic image formation model [33,34], the researcher explored the impact of tourist involvement as the antecedent on cognitive, affective, and conative images in the context of virtual tourism. Preceding studies related to social media [57] and wine products [20] have investigated the influence of involvement on the tourist destination image but only verified the impact of involvement on cognitive and affective images. Festival research examined the correlation between personal involvement and the three destination image components and found that involvement has an influence on cognitive and affective images but has no significant impact on the conative image [21]. The current study confirmed the positive relationship between tourist involvement in cognitive, affective, and conative images, which had not been identified in previous studies.

The conative image indicates that tourists are actively considering the possibility of taking the present destination as a potential target destination [32]. This possibility implies the expected and ideal future tourism condition of tourists, which can influence their behavior intention. Some studies, particularly on the assessment of the effects of cognitive-affective-conative, have been conducted; most researchers believe that cognitive and affective images jointly affect the formation of the conative image of tourists $[27,31,85]$. However, past studies found that such a result is rare based on the verified model, wherein the conative image has the strongest influence on the holistic image of tourists [34]. This paper highlights that the conative image should be distinct and imperative and can independently affect the holistic image evaluation of tourist destinations by tourists.

The concept of the holistic image involves the element of tourists' attitude toward the destination reflected on the behavioral intention, which is amenable for evaluation and measurement in the context of tourism [86]. The high mean score of holistic image denotes that prospective tourists are willing to utilize virtual tourism to obtain the outline and concept of the destination. Past research has shown that prospective visitors are most influenced by the holistic image of the destination, which will also influence their intention to spread word-of-mouth [87]. The findings reveal the substantial strength of the research model in interpreting holistic images. That is, cognitive, affective, and conative images obtained through virtual tourism in a non-immersive VR environment can effectively predict the holistic image of prospective tourists on places that present travel opportunities.

Previous investigations on virtual tourism mostly focused on tour experience [40], destination attitude, and travel intention $[38,66,67]$ and only slightly discussed the relationship between presence and destination image. A few studies, such as that of Hyun and $\mathrm{O}^{\prime}$ Keefe [71], found the correlation between telepresence and cognitive and conative images. Wu and Lai [70] recently confirmed that presence can positively affect cognitive, affective, and holistic images, but exploration of the indirect relationship is lacking. This 
study confirmed that a sense of presence can positively moderate the relationship between the three destination image components (cognitive, affective, and conative images) and the holistic image. The author believes that this study is the first to apply the sense of presence as a moderator to evaluate its impact on shaping the holistic image, providing a new and insightful initiative on virtual tourism.

\subsection{Practical Implications}

At the moment, when COVID-19 is still affecting travel activities worldwide, virtual tourism can cater to risk-conscious travelers to have a feeling of tourism without fear [88]. From the perspective of sustainable development, the travel restrictions and lockdowns have shifted the world from over-tourism to under-tourism. However, this phenomenon is not entirely negative because the reduction in global mobility has a positive impact on climate action and carbon diminution [9], moving the world toward sustainable tourism. Tourist involvement can affect the formation of destination images and influence the intention to travel. Virtual tourism can attract people with environmental awareness or those who want to reduce travel risks, encouraging them to replace on-site tourism with virtual tourism. Such a replacement could lessen carbon emissions effectively by reducing mobility and maintaining the ecological condition of the earth, moving toward the ultimate goal of sustainable development.

Tourism managers and destination marketers are devoting all their efforts to promoting tourism attractions to the masses of the world. Enhancing involvement is a good way to advance the destination image. Therefore, destination marketing organizations may consider increasing tourist involvement through appropriate links. Considering improvements in cognitive images, virtual tourism videos in tourist destinations can connect with social media platforms, and the previous experienced visitors could answer relevant questions about the destination, thus allowing prospective tourists to obtain additional information. Considering promoting an affective image, tour operators can exploit interesting travel posts and feature films of tourists in the places they visit to enhance the entertainment of the film to evoke positive feelings from the viewers. Considering conative image enhancement, prospective tourists can have the opportunity to experience local life or cooking displays, such as cuisine teaching and fruit winemaking, allowing tourists to experience local culture and effectively improve their conative image of the destination. Such an opportunity will generate a beneficial holistic image among prospective visitors and gradually build the impression toward the destination worth visiting.

The results of the study confirmed that a sense of presence can be employed to strengthen the relationship between destination image (cognitive, affective, and conative images) and holistic image. Thus, promoting the sense of presence can effectively improve the holistic image of the tourist destination. The sense of presence is a feeling as if one is in the scene of the destination. Therefore, ambient forms of functions can be added to virtual tourism video content to make tourists feel as they were situated in the destination. Tourism promotion agencies can also develop or add virtual tourism functions based on the context when tourists have on-site visits to increase the accessibility; for example, in a virtual tourism context with real-time commentary from local tour guides and immediate access to tour guides. Visitors can take photos of beautiful scenery during the virtual tourism and click to enter local shops to purchase products. Contacting and interacting with residents to exchange life experiences and share cultural activities may also facilitate an enhanced sense of presence just as on the on-site tour.

The pandemic continues, and the world remains in crisis. Virtual tourism provides a timely and temporary solution for prospective tourists. However, the majority of people may still adopt and want to use virtual tourism even after the pandemic. Consequently, on-site tourism is expected to coexist with virtual tourism simultaneously $[11,89]$. Therefore, formulating marketing strategies for virtual tourism targeting tourism consumers with different functional needs is necessary [89]. The author suggests that destination marketing organizations should properly design the itinerary of virtual tourism for tourists 
who take virtual tourism as a substitute for on-site tourism and increase the interaction between tourists and the destination to enhance and generate similar awareness of visitors as on-site tourism. Meanwhile, for tourists who regard virtual tourism as an information search, detailed local information can be provided to satisfy their effort to acquire tourism knowledge.

\section{Limitations and Future Research}

Similar to any study, some research limitations must be stated. First, the investigation of this study was under an unstable environment during the outbreak of the pandemic. From the sample profile, it can be seen that the majority of respondents (85\%) were above college or university education level. This might indicate that those with higher education might be more interested in virtual tourism. It is recommended that future research be extended to discuss this issue. In addition, respondents were from a limited geographical area; thus, it may be problematic to generalize the research model to other countries or regions. Therefore, it is suggested that the proposed model be extended to other regions with different cultural characteristics to verify the generalization extent of the model. Second, computers and mobile phones are the common accesses accepted by most people; thus, such access almost has no time and place limit. Surfing on the Internet has become the major means of searching for travel information during the pandemic [7]. Therefore, this study adopted non-immersive virtual tourism for the investigation to reach the widest range of prospective tourists. The feelings of virtual tourism may vary depending on the device that respondents utilized due to the survey means of the self-reported questionnaire. Future studies are suggested to examine different virtual tourism environments, such as semi-immersive or fully immersive methods, to implement $360^{\circ} \mathrm{VR}$ video, and compare whether respondents will have different levels of perception on the destination images due to VR devices. Third, the current study only targeted prospective tourists and excluded past tourists who had tourism experience in the destination. Future research can also consider extending the research subject to past tourists and compare differences between the two groups. Fourth, the single factor involvement was employed as the antecedent of the tourist destination image when establishing the model. Future research can supplement other variables, such as familiarity and experience of tourist destinations, which will affect the formation of the tourist destination image. Last, although the research model successfully verified the moderating role of sense of presence, future research can consider using other specific virtual tourism components, such as immersion, interactivity, and imagination, to validate whether these factors can enhance the formation of a holistic image.

Funding: This research received no external funding.

Institutional Review Board Statement: Not applicable.

Informed Consent Statement: Not applicable.

Data Availability Statement: The data presented in this study are available upon request from the corresponding author.

Conflicts of Interest: The author declares no conflict of interest.

\section{Appendix A}

\section{Survey Constructs and Items}

1. Tourist Involvement (adapted from Altunel \& Erkurt, 2015; Kuhzady et al., 2020)

(1) I identify with people that join virtual tourism.

(2) Travel is very significant for me.

(3) Travel matters a lot to me.

(4) I find a lot of my life is organized around holiday trips.

(5) I like to discuss holiday trips with my friends. 
2. Cognitive Image (adapted from Kim et al., 2020; Kim et al., 2017)

(1) I gained knowledge from joining this virtual tourism.

(2) Joining this virtual tourism was useful to collect information.

(3) Joining this virtual tourism provided me with interesting culture events and heritages.

(4) Joining this virtual tourism was beneficial and a good value.

3. Affective Image (adapted from Wu \& Liang, 2020)

(1) I think this virtual tourism was exciting.

(2) I think this virtual tourism was an arousing activity.

(3) I think this virtual tourism was pleasant.

(4) I think this virtual tourism was relaxing.

4. Conative Image (adapted from Kim et al., 2017; Stylidis, 2020)

(1) After joining the virtual tourism, I intend to someday visit the target destination.

(2) After joining the virtual tourism, I have a willingness to speak positively about the target destination.

(3) After joining the virtual tourism, I would recommend the target destination.

(4) After joining the virtual tourism, I would encourage my friends to visit the target destination.

5. Holistic Image (adapted from Hernández-Mogollón, 2018; Kuhzady et al., 2020)

(1) Virtual tourism builds preferable images of target destinations.

(2) Virtual tourism builds favorable images of target destinations.

(3) Virtual tourism builds positive images of target destinations.

(4) In general, after joining a virtual tourism, I would consider staying at the target destination.

6. $\quad$ Sense of Presence (adapted from Yang et al., 2021)

(1) When joining a virtual tourism, I feel the normal experience of being in a tourist destination.

(2) When joining a virtual tourism, the destination feels real to me.

(3) When I think back about a virtual tourism, the images of the destination seem like places I have visited.

(4) While joining a virtual tourism, I often think to myself that I am at the destination.

\section{References}

1. Kuo, C.W. Can we return to our normal life when the pandemic is under control? A preliminary study on the influence of COVID-19 on the tourism characteristics of Taiwan. Sustainability 2021, 13, 9589. [CrossRef]

2. Lim, W.M.; To, W.M. The economic impact of a global pandemic on the tourism economy: The case of COVID-19 and Macao's destination-and gambling-dependent economy. Curr. Issues Tour. 2021, 1-12. [CrossRef]

3. Quang, T.D.; Tran, T.C.; Tran, V.H.; Nguyen, T.T.; Nguyen, T.T. Is Vietnam ready to welcome tourists back? Assessing COVID-19's economic impact and the Vietnamese tourism industry's response to the pandemic. Curr. Issues Tour. 2020, 1-19. [CrossRef]

4. Pappas, N. COVID19: Holiday intentions during a pandemic. Tour. Manag. 2021, 84, 104287. [CrossRef] [PubMed]

5. Rather, R.A. Demystifying the effects of perceived risk and fear on customer engagement, co-creation and revisit intention during COVID-19: A protection motivation theory approach. J. Destin. Mark. Manag. 2021, 20, 100564. [CrossRef]

6. Qiu, R.T.; Park, J.; Li, S.; Song, H. Social costs of tourism during the COVID-19 pandemic. Ann. Tour. Res. 2020, 84, 102994. [CrossRef] [PubMed]

7. Toubes, D.R.; Araújo Vila, N.; Fraiz Brea, J.A. Changes in consumption patterns and tourist promotion after the COVID-19 pandemic. J. Theor. Appl. Electron. Commer. Res. 2021, 16, 75. [CrossRef]

8. Noorashid, N.; Chin, W.L. Coping with COVID-19: The resilience and transformation of community-based tourism in Brunei Darussalam. Sustainability 2021, 13, 8618. [CrossRef]

9. Sharma, G.D.; Thomas, A.; Paul, J. Reviving tourism industry post-COVID-19: A resilience-based framework. Tour. Manag. Perspect. 2021, 37, 100786. [CrossRef]

10. El-Said, O.; Aziz, H. Virtual tours a means to an end: An analysis of virtual tours' role in tourism recovery post COVID-19. J. Travel Res. 2021, 1-21. [CrossRef]

11. Lu, J.; Xiao, X.; Xu, Z.; Wang, C.; Zhang, M.; Zhou, Y. The potential of virtual tourism in the recovery of tourism industry during the COVID-19 pandemic. Curr. Issues Tour. 2021, 1-17. [CrossRef] 
12. Zhang, S.N.; Li, Y.Q.; Ruan, W.Q.; Liu, C.H. Would you enjoy virtual travel? The characteristics and causes of virtual tourists' sentiment under the influence of the COVID-19 pandemic. Tour. Manag. 2022, 88, 104429. [CrossRef]

13. Choi, K.H.; Kim, M.; Leopkey, B. Prospective tourists' risk perceptions and intentions to travel to a mega-sporting event host country with apparent risk. J. Sport Tour. 2019, 23, 97-114. [CrossRef]

14. Grilli, G.; Tyllianakis, E.; Luisetti, T.; Ferrini, S.; Turner, R.K. Prospective tourist preferences for sustainable tourism development in Small Island Developing States. Tour. Manag. 2021, 82, 104178. [CrossRef]

15. Manfredo, M.J. An investigation of the basis for external information search in recreation and tourism. Leis. Sci. 1989, 11, 29-45. [CrossRef]

16. Lu, L.; Chi, C.G.; Liu, Y. Authenticity, involvement, and image: Evaluating tourist experiences at historic districts. Tour. Manag. 2015, 50, 85-96. [CrossRef]

17. Jeong, Y.; Yu, A.; Kim, S.K. The antecedents of tourists' behavioral intentions at sporting events: The case of South Korea Sustainability 2020, 12, 333. [CrossRef]

18. Hou, J.; Lin, C.; Morais, D.B. Antecedents of attachment to a cultural tourism destination: The case of Hakka and Non-Hakka Taiwanese visitors to Pei-Pu, Taiwan. J. Travel Res. 2005, 44, 221-233. [CrossRef]

19. Prayag, G.; Ryan, C. Antecedents of tourists' loyalty to Mauritius: The role and influence of destination image, place attachment, personal involvement, and satisfaction. J. Travel Res. 2012, 51, 342-356. [CrossRef]

20. Wu, G.; Liang, L. Examining the effect of potential tourists' wine product involvement on wine tourism destination image and travel intention. Curr. Issues Tour. 2020, 1-16. [CrossRef]

21. Lee, T.H.; Jan, F.H. How does involvement affect attendees' aboriginal tourism image? Evidence from aboriginal festivals in Taiwan. Curr. Issues Tour. 2021, 24, 2421-2444. [CrossRef]

22. Rahman, A.; Ahmed, T.; Sharmin, N.; Akhter, M. Online destination image development: The role of authenticity, source credibility, and involvement. J. Tour. Q. 2021, 3, 1-20.

23. Crompton, J.L. An assessment of the image of Mexico as a vacation destination and the influence of geographical location upon that image. J. Travel Res. 1979, 17, 18-24. [CrossRef]

24. Gunn, C. Vacationscapes: Designing Tourist Regions; Van Nostrand Reinhold: New York, NY, USA, 1988.

25. Baloglu, S.; McCleary, K.W. A Model of Destination Image Formation. Ann. Tour. Res. 1999, 26, 868-897. [CrossRef]

26. Prayag, G. Tourists' evaluations of destination image, satisfaction, and future behavioral intentions-the case of Mauritius. J. Travel Tour. Mark. 2009, 26, 836-853. [CrossRef]

27. Kim, S.E.; Lee, K.Y.; Shin, S.I.; Yang, S.B. Effects of tourism information quality in social media on destination image formation: The case of Sina Weibo. Inf. Manag. 2017, 54, 687-702. [CrossRef]

28. Pike, S.; Ryan, C. Destination positioning analysis through a comparison of cognitive, affective, and conative perceptions. J. Travel Res. 2004, 42, 333-342. [CrossRef]

29. Myers, J.H. Positioning products/services in attitude space. Mark. Res. 1992, 4, 46-51.

30. Lee, J.S.; Hsu, L.T.; Han, H.; Kim, Y. Understanding how consumers view green hotels: How a hotel's green image can influence behavioural intentions. J. Sustain. Tour. 2010, 18, 901-914. [CrossRef]

31. Agapito, D.; Oom do Valle, P.; da Costa Mendes, J. The cognitive-affective-conative model of destination image: A confirmatory analysis. J. Travel Tour. Mark. 2013, 30, 471-481. [CrossRef]

32. Gartner, W.C. Image formation process. J. Travel Tour. Mark. 1994, 2, 191-216. [CrossRef]

33. Stylos, N.; Bellou, V.; Andronikidis, A.; Vassiliadis, C. Linking the dots among destination images, place attachment, and revisit intentions: A study among British and Russian tourists. Tour. Manag. 2017, 60, 15-29. [CrossRef]

34. Stylos, N.; Vassiliadis, C.; Bellou, V.; Andronikidis, A. Destination images, holistic images and personal normative beliefs: Predictors of intention to revisit a destination. Tour. Manag. 2016, 53, 40-60. [CrossRef]

35. Loureiro, S.M.C.; Jesus, S. How perceived risk and animosity towards a destination may influence destination image and intention to revisit: The case of Rio de Janeiro. Anatolia 2019, 30, 497-512. [CrossRef]

36. Uhm, J.P.; Lee, H.W.; Han, J.W. Creating sense of presence in a virtual reality experience: Impact on neurophysiological arousal and attitude towards a winter sport. Sport Manag. Rev. 2020, 23, 588-600. [CrossRef]

37. Yung, R.; Khoo-Lattimore, C.; Potter, L.E. VR the world: Investigating the effectiveness of virtual reality for destination marketing through presence, emotion, and intention. e-Rev. Tour. Res. 2019, 17, 368-384.

38. Alyahya, M.; McLean, G. Examining tourism consumers' attitudes and the role of sensory information in virtual reality experiences of a tourist destination. J. Travel Res. 2021, 1-16. [CrossRef]

39. Zhang, W.; Wang, Y.; Zhang, T. Can "live streaming" really drive visitors to the destination? From the aspect of "social presence". SAGE Open 2021, 11, 21582440211006691. [CrossRef]

40. Yang, T.; Lai, I.K.W.; Fan, Z.B.; Mo, Q.M. The impact of a $360^{\circ}$ virtual tour on the reduction of psychological stress caused by COVID-19. Technol. Soc. 2021, 64, 101514. [CrossRef] [PubMed]

41. Cao, X.; Qu, Z.; Liu, Y.; Hu, J. How the destination short video affects the customers' attitude: The role of narrative transportation. J. Retail. Consum. Serv. 2021, 62, 102672. [CrossRef]

42. Bogicevic, V.; Seo, S.; Kandampully, J.A.; Liu, S.Q.; Rudd, N.A. Virtual reality presence as a preamble of tourism experience: The role of mental imagery. Tour. Manag. 2019, 74, 55-64. [CrossRef] 
43. Tussyadiah, I.P.; Wang, D.; Jung, T.H.; tom Dieck, M.C. Virtual reality, presence, and attitude change: Empirical evidence from tourism. Tour. Manag. 2018, 66, 140-154. [CrossRef]

44. Kuhzady, S.; Çakici, C.; Olya, H.; Mohajer, B.; Han, H. Couchsurfing involvement in non-profit peer-to-peer accommodations and its impact on destination image, familiarity, and behavioral intentions. J. Hosp. Tour. Manag. 2020, 44, 131-142. [CrossRef]

45. Lo, W.H.; Cheng, K.L.B. Does virtual reality attract visitors? The mediating effect of presence on consumer response in virtual reality tourism advertising. Inf. Technol. Tour. 2020, 22, 537-562. [CrossRef]

46. Wreford, O.; Williams, N.L.; Ferdinand, N. Together alone: An exploration of the virtual event experience. Event Manag. 2019, 23, 721-732. [CrossRef]

47. Huang, Y.C.; Backman, S.J.; Backman, K.F.; Moore, D. Exploring user acceptance of 3D virtual worlds in travel and tourism marketing. Tour. Manag. 2013, 36, 490-501. [CrossRef]

48. Guttentag, D.A. Virtual reality: Applications and implications for tourism. Tour. Manag. 2010, 31, 637-651. [CrossRef]

49. Lee, O.; Oh, J.E. The impact of virtual reality functions of a hotel website on travel anxiety. Cyberpsychol. Behav. 2007, 10, 584-586. [CrossRef] [PubMed]

50. Hobson, J.S.P.; Williams, A.P. Virtual reality: A new horizon for the tourism industry. J. Vacat. Mark. 1995, 1, 125-135.

51. Wiltshier, P.; Clarke, A. Virtual cultural tourism: Six pillars of VCT using co-creation, value exchange and exchange value. Tour. Hosp. Res. 2017, 17, 372-383. [CrossRef]

52. Koutsoudis, A.; Arnaoutoglou, F.; Chamzas, C. On 3D reconstruction of the old city of Xanthi. A minimum budget approach to virtual touring based on photogrammetry. A minimum budget approach to virtual touring based on photogrammetry. J. Cult. Herit. 2007, 8, 26-31.

53. Spielmann, N.; Mantonakis, A. In virtuo: How user-driven interactivity in virtual tours leads to attitude change. J. Bus. Res. 2018, 88, 255-264. [CrossRef]

54. Kim, M.J.; Hall, C.M. A hedonic motivation model in virtual reality tourism: Comparing visitors and non-visitors. Int. J. Inf. Manage. 2019, 46, 236-249. [CrossRef]

55. Huang, Y.C.; Backman, K.F.; Backman, S.J.; Chang, L.L. Exploring the implications of virtual reality technology in tourism marketing: An integrated research framework. Int. J. Tour. Res. 2016, 18, 116-128. [CrossRef]

56. Beck, J.; Rainoldi, M.; Egger, R. Virtual reality in tourism: A state-of-the-art review. Tour. Rev. 2019, 74, 586-612. [CrossRef]

57. Molinillo, S.; Liébana-Cabanillas, F.; Anaya-Sánchez, R.; Buhalis, D. DMO online platforms: Image and intention to visit. Tour. Manag. 2018, 65, 116-130. [CrossRef]

58. Fu, H.; Ye, B.H.; Xiang, J.; Reality, T.V. audience travel intentions, and destination image. Tour. Manag. 2016, 55, 37-48. [CrossRef]

59. Scarpi, D.; Mason, M.; Raggiotto, F. To Rome with love: A moderated mediation model in Roman heritage consumption. Tour. Manag. 2019, 71, 389-401. [CrossRef]

60. Sultan, M.T.; Sharmin, F.; Badulescu, A.; Gavrilut, D.; Xue, K. Social media-based content towards image formation: A new approach to the selection of sustainable destinations. Sustainability 2021, 13, 4241. [CrossRef]

61. Stylidis, D.; Shani, A.; Belhassen, Y. Testing an integrated destination image model across residents and tourists. Tour. Manag. 2017, 58, 184-195. [CrossRef]

62. Wang, C.Y.; Hsu, M.K. The relationships of destination image, satisfaction, and behavioral intentions: An integrated model. J. Travel Tour. Mark. 2010, 27, 829-843. [CrossRef]

63. Lin, C.H.; Morais, D.B.; Kerstetter, D.L.; Hou, J.S. Examining the role of cognitive and affective image in predicting choice across natural, developed, and theme-park destinations. J. Travel Res. 2007, 46, 183-194. [CrossRef]

64. Afshardoost, M.; Eshaghi, M.S. Destination image and tourist behavioural intentions: A meta-analysis. Tour. Manag. 2020, 81, 104154. [CrossRef]

65. Slater, M.; Wilbur, S. A framework for immersive virtual environments (FIVE): Speculations on the role of presence in virtual environments. Presence 1997, 6, 603-616. [CrossRef]

66. Fraustino, J.D.; Lee, J.Y.; Lee, S.Y.; Ahn, H. Effects of 360 video on attitudes toward disaster communication: Mediating and moderating roles of spatial presence and prior disaster media involvement. Public Relat. Rev. 2018, 44, 331-341. [CrossRef]

67. Wei, W.; Qi, R.; Zhang, L. Effects of virtual reality on theme park visitors' experience and behaviors: A presence perspective. Tour. Manag. 2019, 71, 282-293. [CrossRef]

68. Yung, R.; Khoo-Lattimore, C.; Prayag, G.; Surovaya, E. Around the world in less than a day: Virtual reality, destination image and perceived destination choice risk in family tourism. Tour. Recreat. Res. 2021, 46, 3-18. [CrossRef]

69. Baños, R.M.; Botella, C.; Alcañiz, M.; Liaño, V.; Guerrero, B.; Rey, B. Immersion and emotion: Their impact on the sense of presence. Cyberpsychol. Behav. 2004, 7, 734-741. [CrossRef] [PubMed]

70. $\mathrm{Wu}, \mathrm{X} . ; \mathrm{Lai}, \mathrm{I} . \mathrm{K} . \mathrm{W}$. Identifying the response factors in the formation of a sense of presence and a destination image from a 360-degree virtual tour. J. Dest. Mark. Manag. 2021, 21, 100640. [CrossRef]

71. Hyun, M.Y.; O'Keefe, R.M. Virtual destination image: Testing a telepresence model. J. Bus. Res. 2012, 65, 29-35. [CrossRef]

72. Altunel, M.C.; Erkurt, B. Cultural tourism in Istanbul: The mediation effect of tourist experience and satisfaction on the relationship between involvement and recommendation intention. J. Dest. Mark. Manag. 2015, 4, $213-221$.

73. Kim, M.J.; Lee, C.K.; Jung, T. Exploring consumer behavior in virtual reality tourism using an extended stimulus-organismresponse model. J. Travel Res. 2020, 59, 69-89. [CrossRef] 
74. Stylidis, D. Exploring Resident-Tourist Interaction and its Impact on Tourists' Destination Image. J. Travel Res. 2022, 61, 186-201. [CrossRef]

75. Hernández-Mogollón, J.M.; Duarte, P.A.; Folgado-Fernández, J.A. The contribution of cultural events to the formation of the cognitive and affective images of a tourist destination. J. Dest. Mark. Manag. 2018, 8, 170-178. [CrossRef]

76. Chin, W.W.; Marcolin, B.L.; Newsted, P.R. A partial least squares latent variable modeling approach for measuring interaction effects: Results from a Monte Carlo simulation study and an electronic-mail emotion/adoption study. Inf. Syst. Res. 2003, 14, 189-217. [CrossRef]

77. Chin, W.W. The partial least squares approach to structural equation modeling. Mod. Methods Bus. Res. 1998, 2, $295-336$.

78. Hair, J.F.; Sarstedt, M.; Ringle, C.M.; Mena, J.A. An assessment of the use of partial least squares structural equation modeling in marketing research. J. Acad. Mark. Sci. 2012, 40, 414-433. [CrossRef]

79. Anderson, J.C.; Gerbing, D.W. Structural equation modeling in practice: A review and recommended two-step approach. Psychol. Bull. 1988, 103, 411-423. [CrossRef]

80. Hair, J.F., Jr.; Hult, G.T.M.; Ringle, C.; Sarstedt, M. A Primer on Partial Least Squares Structural Equation Modeling (PLS-SEM); Sage Publications: Washington, DC, USA, 2016.

81. Hair, J.F.; Risher, J.J.; Sarstedt, M.; Ringle, C.M. When to use and how to report the results of PLS-SEM. Eur. Bus. Rev. 2019, 31, 2-24. [CrossRef]

82. Falk, R.F.; Miller, N.B. A Primer for Soft Modeling; University of Akron Press: Akron, OH, USA, 1992.

83. Cohen, J. Statistical Power Analysis for the Behaviors Science, 2nd ed.; Lawrence Erlbaum Associates: Hillsdale, NJ, USA, 1988.

84. Fassott, G.; Henseler, J.; Coelho, P.S. Testing moderating effects in PLS path models with composite variables. Ind. Manag. Data Syst. 2016, 116, 1887-1900. [CrossRef]

85. Woosnam, K.M.; Stylidis, D.; Ivkov, M. Explaining conative destination image through cognitive and affective destination image and emotional solidarity with residents. J. Sustain. Tour. 2020, 28, 917-935. [CrossRef]

86. Nadeau, J.; Heslop, L.; O'Reilly, N.; Luk, P. Destination in a country image context. Ann. Tour. Res. 2008, 35, 84-106. [CrossRef]

87. Papadimitriou, D.; Kaplanidou, K.; Apostolopoulou, A. Destination image components and word-of-mouth intentions in urban tourism: A multigroup approach. J. Hosp. Tour. Res. 2018, 42, 503-527. [CrossRef]

88. Rather, R.A. Monitoring the impacts of tourism-based social media, risk perception and fear on tourist's attitude and revisiting behaviour in the wake of COVID-19 pandemic. Curr. Issues Tour. 2021, 1-9. [CrossRef]

89. Itani, O.S.; Hollebeek, L.D. Light at the end of the tunnel: Visitors' virtual reality (versus in-person) attraction site tour-related behavioral intentions during and post-COVID-19. Tour. Manag. 2021, 84, 104290. [CrossRef] 